\title{
Regeneration of Corticospinal Axons in the Rat
}

\author{
Earl R. Feringa, MD, Lawrence M. Shuer, BA, H. Lee Vahlsing, MS, \\ and Sam W. Davis, BS
}

In the rat, a few long descending motor tracts capable of carrying an impulse and causing a propagated impulse in the ipsilateral sciatic nerve will regenerate after complete spinal cord transection. In this experiment such regeneration was found in both treated and control animals.

Orthograde axonal transport of tritiated proline injected into the motor cortex labels only the corticospinal tracts in the rat spinal cord. Scintillation counts of measured lengths of spinal cord can be used as a measure of the number of labeled corticospinal axons.

Comparison of radioactivity per unit length of measured cord segments taken from above and below the site of a previous spinal cord transection can give a reliable estimate of the number of labeled axons that regenerated and crossed the site of injury. Using this test we have demonstrated that some corticospinal axons had regenerated six months after spinal cord transection in control animals, animals made tolerant to degenerating spinal cord antigens, and animals treated with cyclophosphamide. A group treated with a single $75 \mathrm{mg}$ per kilogram dose of cyclophosphamide 24 hours after spinal cord transection showed the best evidence of corticospinal tract regeneration.

Feringa ER, Shuer LM, Vahlsing HL, et al: Regeneration of corticospinal axons in the rat. Ann Neurol 2:315-321, 1977

In several recent experiments we have demonstrated electrophysiological evidence of regeneration of long descending motor tracts in the rat spinal cord after immunosuppressive therapy [1, 2, 4]. Evidence for such regeneration was found in animals treated with a variety of methods to alter their immune response, but the best results were obtained in animals given a large single injection of cyclophosphamide 1 hour after spinal cord transection. Functional recovery in terms of walking behavior was not observed, but following a midthoracic spinal cord transection, electrical stimulation of the descending motor pathways in the high cervical cord resulted in a propagated impulse in the ipsilateral sciatic nerve with conduction velocity identical or very close to that in animals which had never had a spinal cord lesion.

This experiment was an effort to verify and to improve the regenerative potential of intraspinal axons in spinal cord transected animals and to search for additional evidence of descending motor tract regeneration.

\section{Materials and Methods}

Rats in this study were derived from Wistar rats and were inbred for 74 generations of brother-sister matings to assure isogeneic animals; skin transplantation studies have demon- strated that the rats are in fact isogeneic. Four animal groups were studied. Each animal had a complete spinal cord transection at 6 weeks of age. The completeness of the spinal cord transection was always verified by two investigators.

Group 1 contained 13 rats that had no treatment prior to spinal cord transection and were given a single intraperitoneal injection of $0.4 \mathrm{ml}$ of isotonic saline 1 hour after the transection.

Group 2 contained 13 rats that received no treatment prior to spinal cord transection. They were treated with a single intraperitoneal in jection of cyclophosphamide, $75 \mathrm{mg}$ per kilogram of body weight, in $0.4 \mathrm{ml}$ of isotonic saline within 1 hour after spinal cord transection.

Group 3 contained 13 rats that received no treatment before spinal cord transection. These animals were given a single injection of $75 \mathrm{mg} / \mathrm{kg}$ cyclophosphamide in $0.4 \mathrm{ml}$ of saline administered 24 hours after spinal cord transection. This delayed treatment was performed because the studies of Paterson and Hanson [10] demonstrated that cyclophosphamide is effective in preventing experimental allergic encephalitis when given 48 hours after sensitization to CNS antigens. Other reports $[8,11,13,14]$ indicate that $c y-$ clophosphamide might be expected to be more effective if it is administered after exposure to antigen at a time when a clone of sensitized lymphocytes is rapidly dividing.

Group 4 consisted of 15 rats that had been given an intraperitoneal injection of degenerating spinal cord tissue within the first 24 hours of life in an effort to make them
From the Departments of Neurology and Pathology, Veterans Administration Hospital and the Universiry of Michigan Medical Center, Ann Arbor, MI.
Address reprint requests to Dr Feringa, Neurology Service/127, Veterans Administration Hospital, 2215 Fuller Rd, Ann Arbor, MI 48105 .

Accepted for publication May 16, 1977. 
tolerant to spinal cord antigens [9]. Lynch, as reported by Guth [5], has suggested that growth of central axon sprouts might be inhibited in an area of brain that contains degenerating, recently injured axons. Because our previous efforts $[1,2,4]$ to induce tolerance to CNS antigens by neonatal exposure to normal spinal cord tissue had not produced dramatic improvement in spinal cord regeneration, in the present experiment we attempted to induce tolerance to degenerating cord in the hope that this might improve the opportunity for regeneration.

To prepare an antigenic suspension of degenerating spinal cord, we performed a complete spinal cord transection at a high thoracic level in 12-week-old rats. Ten days later these animals were sacrificed by exsanguination under ether anesthesia. The spinal cord below the site of the previous spinal cord transection was homogenized in an equal volume of isotonic saline over an ice bath, and $0.2 \mathrm{ml}$ of this homogenate was injected intraperitoneally during the first 24 hours of life into each experimental rat in Group 4 in an effort to induce tolerance to antigens contained in degenerating spinal cord.

Following spinal cord transection the animals were placed in separate cages. The bladders were emptied by the method of Credé every 8 hours until reflex bladder control returned in approximately two weeks. Decubitus ulcers, which developed rarely, were cleaned and debrided as necessary. Abnormalitics of tooth growth in the rats treated with $c y$ clophosphamide $[15,16]$ were treated by clipping extra-long teeth and placing the animals on a diet of soft food.

\section{Electropbysiological Evaluation}

All rats were evaluated for evidence of electrophysiological return of long descending motor pathways as previously described $[1,4]$. In each case, immediately prior to sacrifice the animal was anesthetized and the sciatic nerve was isolated and placed in a recording electrode apparatus. The spinal cord was then exposed in the high cervical area. The animals were immobilized in a stereotactic apparatus and given curare to cause neuromuscular blockade. Respiration was maintained with a mask and a positive-pressure respiratory device.

Using a concentric bipolar electrode and a constantcurrent stimulator, stimuli of 0.2 to $7 \mathrm{ma}$ for $0.35 \mathrm{msec}$ duration were then applied to the dorsal column area where the descending corticospinal tracts lie in the rat $[6,7,12]$. Efforts were made to pick up an evoked response in the ipsilateral sciatic nerve, which was time-locked to stimulation of the descending motor tract. In addition to observed and photographed responses on the cathode ray oscilloscope (CRO), 80 to 100 consecutive stimulus/response curves for each animal were recorded on tape and later averaged using a computer of average transients. Electrical responses were graded at the time of stimulation as present, absent, or questionable. Photographic summations of multiple stimulus/response curves from the CRO were independently evaluated at a later date and recorded as positive, negative, or questionable. The computer-averaged curves were similarly evaluated and recorded as positive, negative, or questionable.

At the end of the experiment all observations on each animal were reviewed. On the basis of all information, each animal was assigned to a group according to whether it showed definite evidence of electrical conduction or not. The code was broken and final tables prepared only after this determination had been made blindly.

\section{Radioisotopic Evaluation}

In addition to the electrophysiological end-point, in this study we utilized the axonal transport of intracerebrally injected tritiated proline into and across the area of spinal cord transection to measure the degree of corticospinal tract regeneration.

Commercially available tritiated proline was dessicated to dry powder and resuspended in a known volume of lactated Ringer's solution to produce a suspension containing 100 $\mu \mathrm{Ci}$ of radioactive proline per $5 \mu$ l of solution. Twenty-one days before the planned electrophysiological evaluation (six months after spinal cord transection), the animals were anesthetized and placed in a stereotactic apparatus. The skull was exposed and a $1 \mathrm{~mm}$ burr hole was made on each side to permit injection of radioisotope into the area of cerebral cortex containing the cell bodies that give rise to the corticospinal tract in the rat [7]. Using a micromanipulator and a short, beveled, 30-gauge needle, $2.5 \mu \mathrm{l}$ of tritiated proline was injected at a depth of $1 \mathrm{~mm}$ beneath the pial surface. After a 1-minute delay the needle was withdrawn and a similar injection was performed into the contralateral cortex.

Twenty-one days after in jection of the tritiated proline, these animals were first tested electrophysiologically for evidence of long descending motor tract function and then were sacrificed by perfusion under anesthesia.

The entire spinal column and cord from the foramen magnum to the sacral area was excised, and the spinal column was removed from the cranial and caudal ends of the spinal cord (Fig 1). A $2 \mathrm{~cm}$ area of cord was left encased in its dura and surrounding bony tissue in the area centered about the point of previous spinal cord transection to avoid disturbing that site (area $D$ in Fig 1). Small portions of distal and proximal spinal cord (areas $C$ and $E$, Fig 1) were removed for histological study. Larger measured sections of spinal cord (areas $B$ and $F$, Fig 1 ) were taken from the cervical segment and thoracolumbar section of the cord for scintillation counting study. The cervical segment (area $B$ ) extended approximately from $\mathrm{C}-1$ to $\mathrm{C}-6$ and the thoracolumbar section (area $F$ ) from $\mathrm{T}-9$ to $\mathrm{L}-2$.

Cross-sections of the smaller sections of the cord (areas $C$ and $E$ ) were cut at $6 \mu \mathrm{m}$ and dipped in NTB 2 emulsion. They were then exposed for 35 days in a light-tight box and developed for 2 minutes in full-strength developer. The slides were labeled by one investigator using a code unknown to the two observers who evaluated for autoradiographic evidence of axonal regeneration.

Each of the larger cord samples (areas $B$ and $F$ ) was weighed and the length recorded. Then, after solubilization, the tissue was counted in a scintillation counter. The disintegrations per minute (dpm) per unit length were determined for each segment of spinal cord. To evaluate evidence for regenerated axons across the site of spinal cord transection, each animal was used as its own control. The dpm per unit length in the cervical region was highly variable, depending on the skill with which we had injected the cerebral 


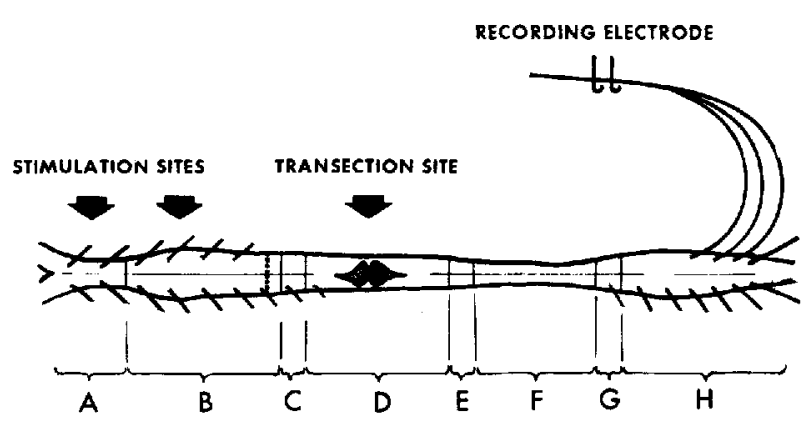

Fig 1. The rat spinal cord, from cranial to caudal end. The points where electrical stimulation was applied (A), the site of spinal cord transection (D), and the point used to record propagated electropbysiological response (the ipsilateral sciatic nerve) are indicated. Areas $\mathrm{B}$ and $\mathrm{F}$ were studied by scintillation counting to estimate the relative number of labeled axons in each. Areas $\mathrm{C}$ and $\mathrm{E}$ were used to prepare cross-section autoradiograms. Area $\mathrm{D}$ was studied by serial-section longitudinal autoradiograpby. Areas $\mathrm{G}$ and $\mathrm{H}$ were not useful in the final evaluation.

cortex and the accuracy of our estimate of the location of the cortical motor area. Therefore, the measure of regenerated axons assigned to each animal was the dpm per unit length detected in the thoracolumbar segment (area $F$ ) expressed as a percentage of the $\mathrm{dpm}$ per unit length in the cervical region (area $B$ ).

Longitudinal autoradiograms were performed on a few animals that showed electrophysiological evidence of regeneration. In these studies, longitudinal sections of the area of transection were prepared. After decalcification, the segment labeled $D$ in Figure 1 was serially sectioned and representative sections were coated with emulsion and exposed in a light-tight box for two weeks. After developing and staining, the slides were studied with a dark-field microscope.

\section{Results}

Stimulation of the corticospinal tract area in the cervical spinal cord was followed by a time-locked response in the ipsilateral sciatic nerve in a total of 16 of the 54 animals. Such evidence of regeneration was found in each group, including the control animals (Table 1). No significant differences were noted between the groups.
Table 1. Electropbysiological Testing ${ }^{a}$

\begin{tabular}{lll}
\hline Group & $\begin{array}{l}\text { No. of Rats } \\
\text { Tested }\end{array}$ & $\begin{array}{l}\text { No. Showing } \\
\text { Regeneration }\end{array}$ \\
\hline 1 (control rats) & 13 & 3 \\
2 (cyclophosphamide & 13 & 4 \\
$\quad$ at 1 hr) & & \\
3 (cyclophosphamide & 13 & 4 \\
$\begin{array}{l}\text { at 24 hr) } \\
\text { (tolerant) }\end{array}$ & 15 & 5 \\
\hline
\end{tabular}

a Some electrophysiological evidence of regeneration of long descending motor pathways is seen in each group. No significant differences are noted between the groups.

Autoradiograms of cross-sections were evaluated blind for evidence of labeled regenerated corticospinal axons. In the control sections, taken from above the site of spinal cord transection, very heavily labeled fibers were closely grouped in the most ventral aspect of the dorsal columns; this has been well established as the location of corticospinal tracts in the rat $[6,7,12]$. No other pathways were labeled (Fig 2). A very mild background of reduced silver grains was present.

In those cross-sections taken from below the site of transection, no group of labeled fibers could be identified. Two observers independently counted the absolute number of silver grains seen in a measured square $\left(0.002 \mathrm{~mm}^{2}\right)$ in five designated areas: the background, i.e., emulsion adjacent to the histological specimen; in the usual location of the corticospinal tract; over the ventral horn gray area; over the dorsal horn gray area; and in the region of the lateral white column. These counts were then subjected to computer analysis. The findings of the two observers correlated well, but there was no evidence of a difference between treated and control animals. The background of reduced silver grains, although small, interfered to a considerable degree with our attempts to use this method to evaluate regeneration, because a labeled fiber in cross-section could show as only a single grain of reduced silver and therefore be impossible to separate from background.

Table 2 shows mean scintillation counts in the thoracolumbar cord, expressed as a percentage of activity found in the cervical region of the same animal

Table 2. Scintillation Data

\begin{tabular}{lclccc}
\hline Group & Mean & No. of Rats & Variance & \pm & Significance \\
\hline 1 (control rats) & 8.9 & 13 & 27.0 & $\ldots$ & $\ldots$ \\
2 (cyclophosphamide at 1 hr) & 11.9 & 13 & 142.0 & -0.85 & $p=0.20$ \\
3 (cyclophosphamide at 24 hr) & 16.8 & 13 & 179.4 & -1.99 & $p=0.03$ \\
4 (tolerant) & 9.0 & 15 & 101.8 & -0.40 & $p=0.48$ \\
\hline
\end{tabular}

"For each group the amount of radioactivity in the distal spinal cord (below the site of transection) was expressed as a percentage of the radioactivity in a cord segment cranial to the site of transection. Aucoradiograms demonstrated that all radioactivity is restricted to the corticospinal tracts. The percentage of radioactivity seen in the distal cord is therefore an indirect measure of the amount of corticospinal tract regeneration that had occurred. 


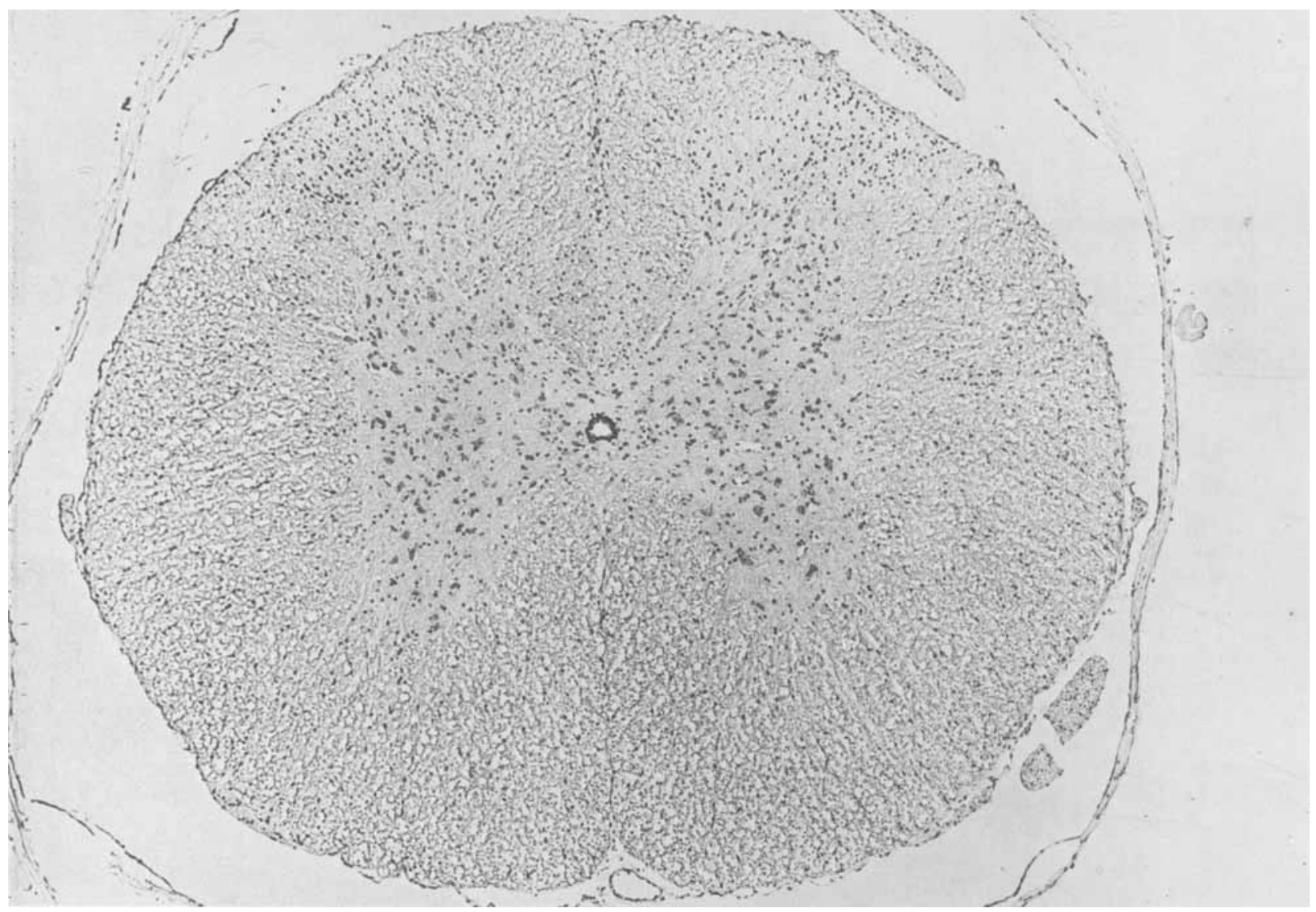

A

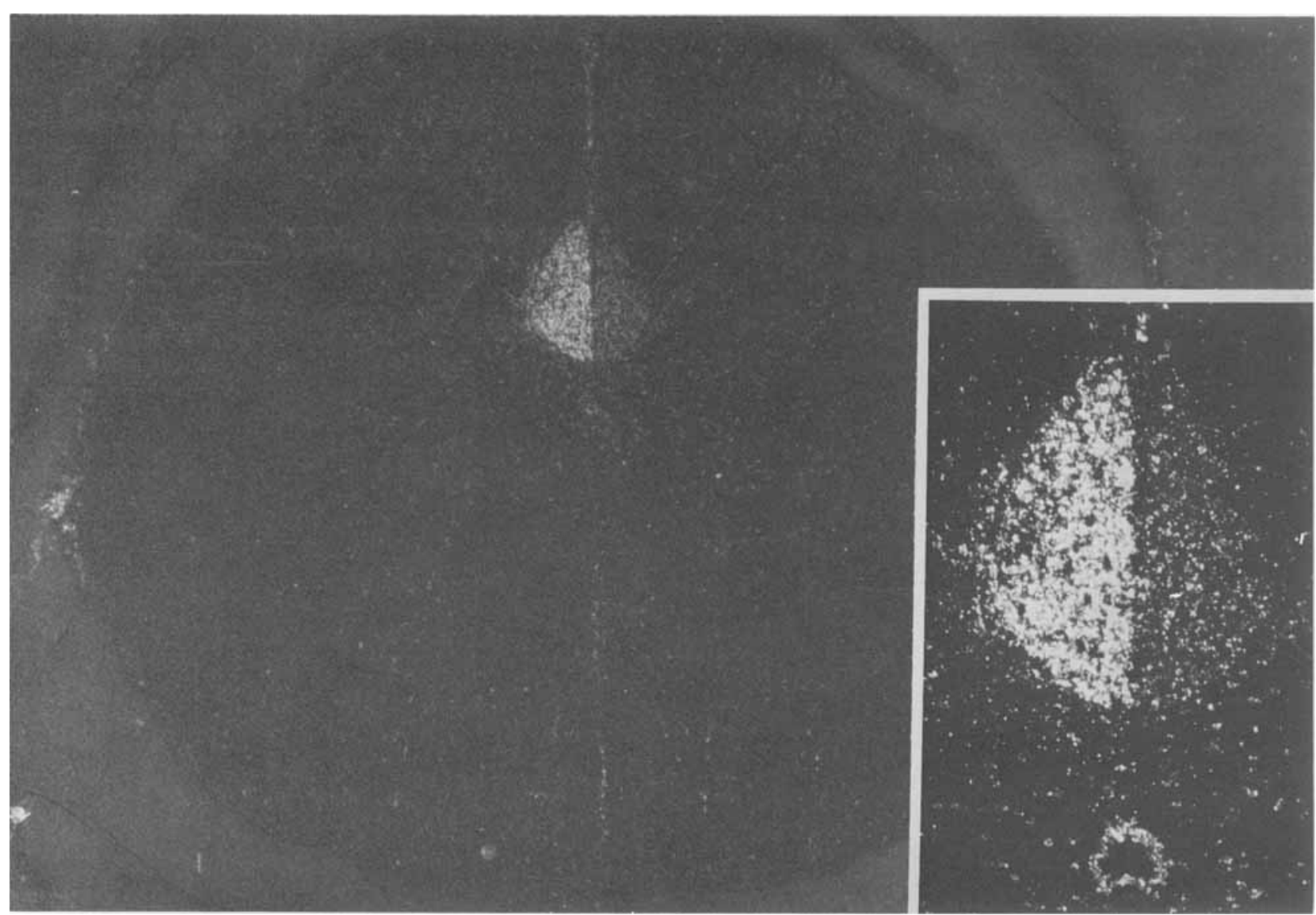

B

318 Annals of Neurology Vol 2 No 4 October 1977 
Fig 2. (A) Low-pouer photomicrograph of an autoradiogram of the spinal cord cranial to the site of spinal cord transection (area $\mathrm{C}$ in Fig 1). At this magnification, reduced silver grains over the area of the labeled corticospinal tract cannot be identified. ( $\times 60$.) (B) Dark-field illumination clearly indicates the autoradiographic label of this tract. The inset is a bigh-power ( $\times 150)$ view of the corticospinal tract and adjacent structures viewed with dark-field illumination. The silver grains sbow as prominent white spots; neuronal cell bodies and some vessels show as bright orange spots. In order to illustrate the silver granules and suppress the otber bright areas, which indicate cells or vessels, the larger photograph in B was prepared by a subtraction technique in which negatives of bright-field and dark-field illumination of the same section were superimposed. Cells and vessels are largely subtracted from the resulting image, leaving the brightly shining silver particles clearly visible. Note that only the corticospinal tracts are labeled; no otber areas of the spinal cord sbow radioactivity. $(\times 60$.)

Fig 3. Dark-field illumination of an autoradiogram showing reduced silver granules over the corticospinal tracts in an area just cranial to the site of spinal cord transection (cranial area of segment $\mathrm{D}$ in Fig 1 ). The tract runs longitudinally in the most inferior portion of the dorsal white columns. Scattered random background grains of reduced silver are seen over adjacent spinal cord, but no strings of grains that would indicate a labeled axon in anotber region. $(\times 100$. for each treatment group, Regeneration was almost identical in the "tolerant" animals and the control group. Rats treated with cyclophosphamide 1 hour after transection showed greater regeneration, but the increase was not significant. Those treated 24 hours after spinal cord transection had a definite increase in regeneration of corticospinal tracts as measured by this test $(p=0.03)$.

In a separate experiment we tested similarly for evidence of regeneration only five weeks after spinal cord transection, a time when it is unlikely that any regeneration could have occurred. In these animals only $2 \%$ of the radioactivity in the cervical region could be detected in the lumbosacral cord. The data for each of the study groups, treated or control, are significantly higher than values obtained in this shortterm group ( $p=0.04-0.003$ )

Dark-field autoradiograms of longitudinal sections were evaluated in search of evidence of labeled regenerated corticospinal axons. Strings of reduced silver granules were prominent in the area of the corticospinal tract cranial to the site of transection (Fig 3). Caudal to the site of transection, at random locations, isolated similar strings of reduced silver granules served to identify regenerated corticospinal axons distal to the transection site (Fig 4). These labeled axons ran in a longitudinal direction, mixed with other fiber tracts. They did not gather together as a tract but

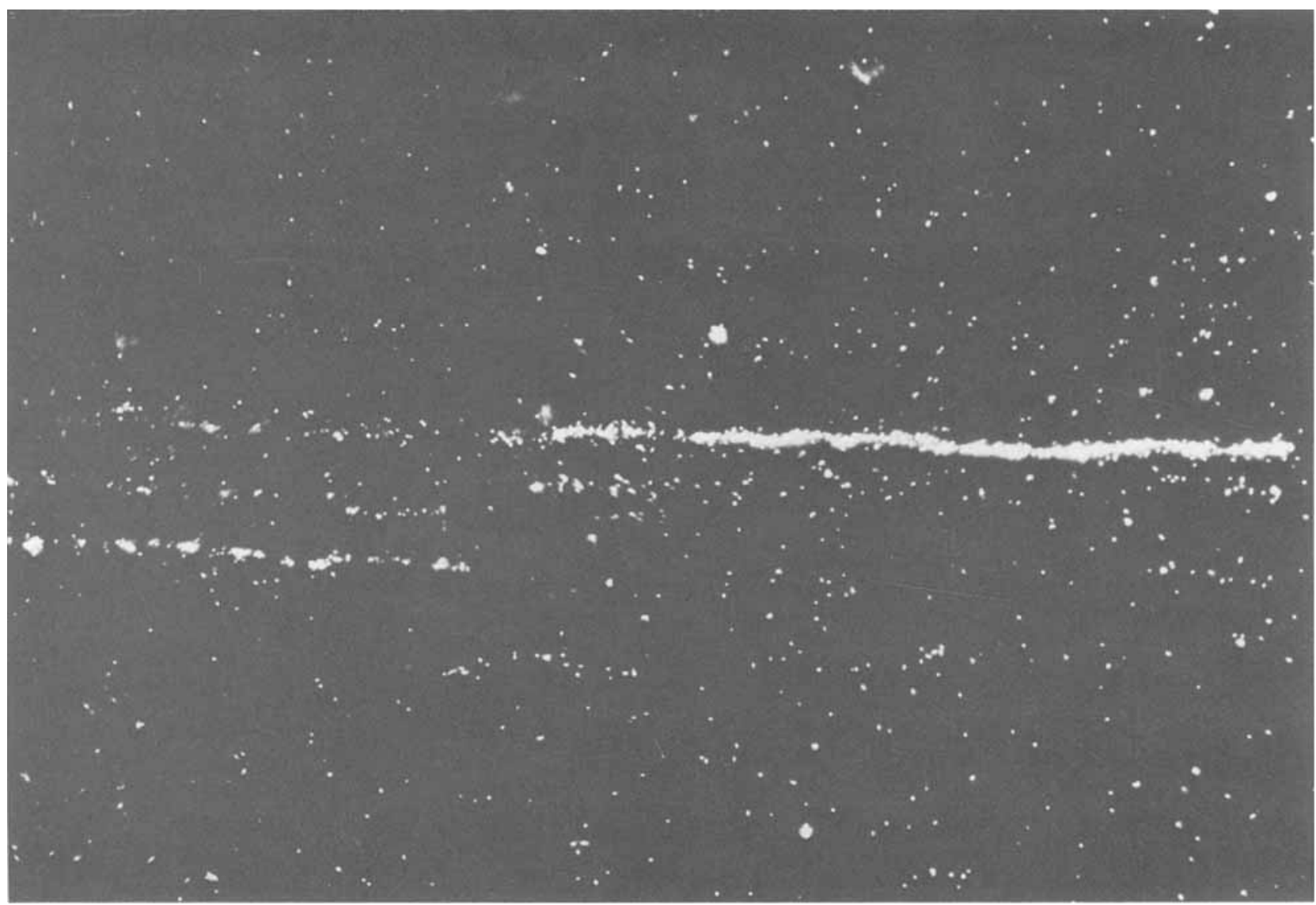




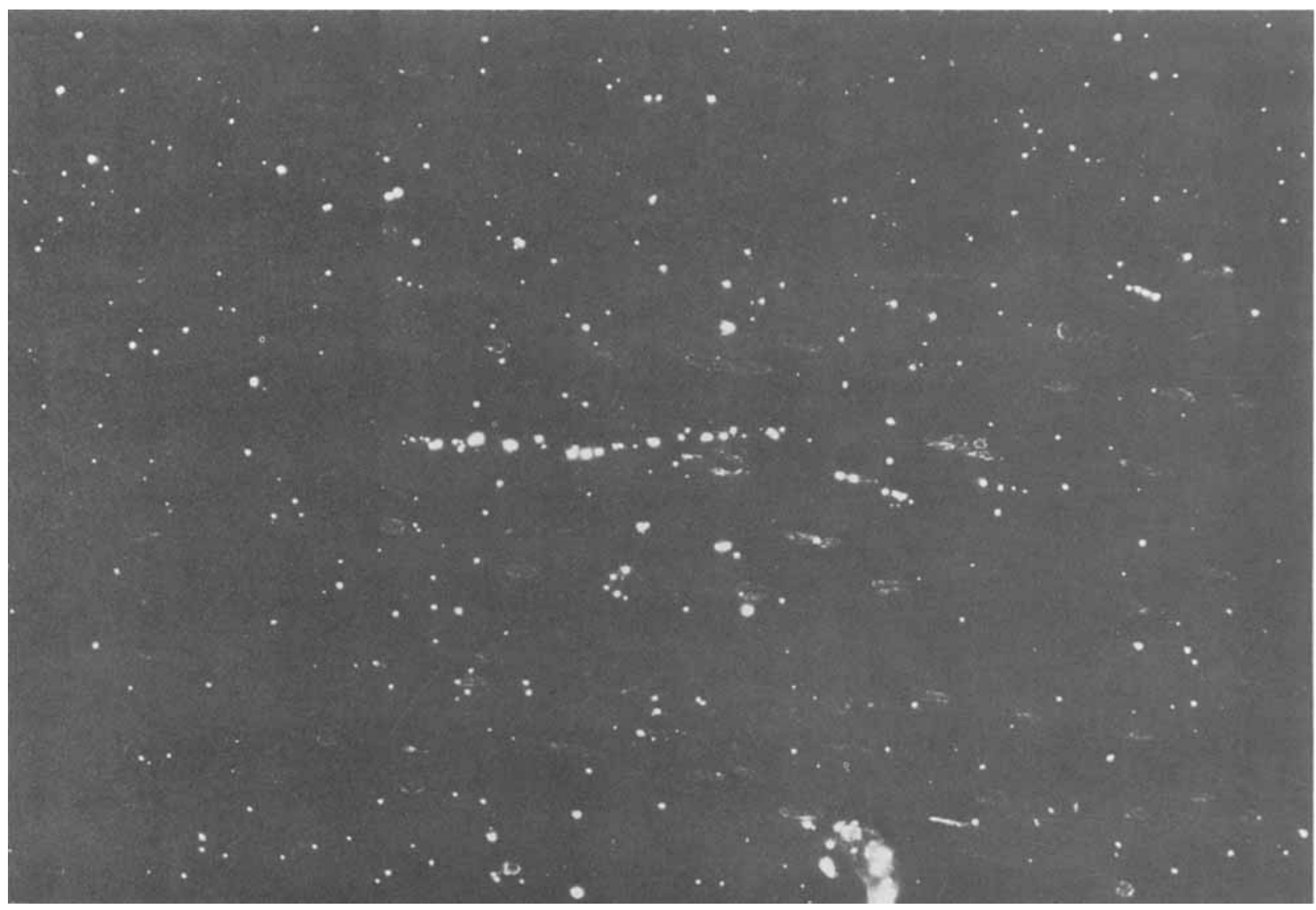

rather coursed caudally as individual fibers in no particular area of the cord.

\section{Discussion}

In our earlier studies [1-4] of rats having complete spinal cord transection, no electrophysiological evidence of regeneration of long descending motor tracts was found in untreated control animals. Those with incompletely transected cords [3], however, frequently showed an almost normal electrophysiological response. In this study, by using single-sweep CRO tracings, photographic summation of multiple CRO sweeps, and analysis of multiple stimulus/ response tracings with a computer of average transients, we were able to identify an electrophysiological response in more than one-fourth of our animals. No significant differences were found between treatment and control groups.

Some evidence of regeneration was also found in all groups by scintillation counting procedures and, in selected cases, on evaluation of longitudinal autoradiograms. These data support the idea that at least some corticospinal tract regeneration occurred in all groups of animals tested.

The scintillation counting data showed that, compared with controls, more radioactivity reached the distal (thoracolumbar) spinal cord in the animals given
Fig 4. Dark-field illumination of an autoradiogram showing reduced silver granules over a labeled axon in the spinal cord just caudal to the site of spinal cord transection (caudal area of segment $\mathrm{D}$ in Fig 1), Such labeled axons could be identified as single fibers scattered randomly through the white matter of the cord. They ran in a longitudinal direction but did not gather into a "tract" in any specific area of the spinal cord. $(\times 100$.

cyclophosphamide, especially in the group treated at 24 hours. We believe this is an accurate measure of regenerated corticospinal axons because autoradiograms show that all identifiable labeled axons in the cord are restricted to the anatomical location of the corticospinal tracts. Tritiated proline injected into the cerebral cortex as described is taken up by the cortical cells in that location and transported by orthograde axonal flow down the axons of these cells. We have done autoradiograms of the injected area of cortex and demonstrated that radioactivity is rather sharply confined to the point of injection. Diffusion through the brain is limited to an area of about $1 \mathrm{~mm}$ in all directions from the needle tract, and more widespread local diffusion cannot be identified.

Autoradiograms of cross- and longitudinal sections of spinal cord cranial to the site of spinal cord transection show no significant quantity of labeled axons 
except those situated in the established location of the corticospinal tracts. Figure 2 illustrates how well the radioactively labeled axons are restricted to this area. It also shows an example of the variability in intensity of tract labeling on one side compared with the contralateral tract, presumably due to nonidentical cortical in jections of tritiated proline. Such variability not only was noted from side to side in a given animal, but also could be seen in variable raw $\mathrm{dpm}$ per unit length data for the cervical segment of individual animals. Even when this measure indicated that cortical injection was less than optimal, labeled axons in the cord were always restricted to the area of the corticospinal tract.

The amount of radioactivity ultimately reaching the thoracolumbar area via axonal flow in regenerated corticospinal axons clearly depended on the success with which we labeled the axons in this tract in the cervical cord. For this reason, the best measure of the degree of corticospinal axon regeneration was the percentage of activity (labeled axons) in the cervical region that had crossed the point of spinal cord transection and could be detected in the thoracolumbar area.

Treatment with a single high dose of cyclophosphamide 24 hours after spinal cord transection proved most efficacious in permitting corticospinal axonal regeneration. If the drug were acting as an immunosuppressant, this timing would have been expected to be optimal, because approximately 24 hours after first exposure to an antigen a clone of sensitized cells would be rapidly dividing to form a larger pool of immunologically active cells. Cyclophosphamide is most effective in causing cell death in just such rapidly dividing cells. Thus the findings in this experiment are consistent with the hypothesis that immunological factors play a role in inhibiting axonal regeneration in the central nervous system.

The data in this experiment, while consistent with our hypothesis, do not prove an immunological mechanism. Indeed, the group made tolerant to degenerating spinal cord antigens also should have shown improved regeneration, but they did not. Final determination of the mechanism by which our drug treatment facilitates regeneration requires additional and more detailed histological and histochemical studies.
This research was financed by institutional research support of the Veterans Administration Hospital, Ann Arbor, MI, and the University of Michigan Medical Center Fund for Computing.

The authors wish to express their appreciation to Ms Linda Lee Austin for technical assistance, Mrs Edith Cole and Mrs Mary Lou Wander for secretarial aid, and Mr Robert McKnight for assistance with necessary photography.

\section{References}

1. Feringa ER, Gurden GG, Strodel W, et al: Descending spinal motor tract regeneration after spinal cord transection. Neurology (Minneap) 23:599-608, 1973

2. Feringa ER, Johnson RD, Wendt JS: Spinal cord regeneration in rats after immunosuppressive treatment. Arch Neurol 22:676-683, 1975

3. Feringa ER, Kinning WK, Britten AG, et al: Recovery in rats after spinal cord injury. Neurology (Minneap) 26:839-843, 1976

4. Feringa ER, Wendt JS, Johnson RD: Immunosuppressive treatment to enhance spinal cord regeneration in rats. Neurology (Minneap) 24:287-293, 1974

5. Guth $\mathrm{L}$ : Axonal regeneration and functional plasticity in the central nervous system. Exp Neurol 45:606-654, 1974

6. Hicks SP, D'Amato CJ: Motor-sensory and visual behavior after hemispherectomy in newborn and mature rats. Exp Neurol 29:416-438, 1970

7. Hicks SP, D'Amato CJ: Motor-sensory cortex-corticospinal system and developing locomotion and placing in rats. Am J Anat 143:1-42, 1975

8. Many A, Schwartz R: On the mechanism of immunological tolerance in cyclophosphamide-treated mice. Clin Exp Immunol 6:87-99, 1970

9. Paterson PY: Studies of immunological tolerance to nervous tissue in rats. Ann NY Acad Sci 73:811-815, 1958

10. Paterson PY, Hanson MA: Studies of cyclophosphamide suppression of experimental allergic encephalomyelitis in Wistar rats. J Immunol 103:795-803, 1969

11. Paterson PY, Hanson MA: Cyclophosphamide inhibition of experimental allergic encephalomyelitis and cellular transfer of the disease in Lewis rats. J Immunol 103:1311-1316, 1969

12. Ranson SW: The fasciculus cerebro-spinalis in the albino rat. Am J Anat 14:411-426, 1943

13. Salvin SB, Smith RF: The specificity of allergic reactions. J Exp Med 119:851-868, 1964

14. Santos GW: Immunosuppressive drugs. Fed Proc 26:907-913, 1967

15. Vahlsing HL, Feringa ER, Britten AH: Dental abnormalities in rats after a single large dose of cyclophosphamide. Cancer Res 35:2199-2202, 1975

16. Vahlsing HL, Kim SK, Feringa ER: Cyclophosphamideinduced abnormalities in the incisors of the rat. J Dent Res (in press) 